\title{
Are electrochemical fences effective in the retention of pollution?
}

\author{
S. Rodrigo ${ }^{a}$, C. Sáez ${ }^{b}$, V. Navarroc ${ }^{c}$ P. Cañizares ${ }^{b}$, M.A. Rodrigo ${ }^{\text {b,* }}$
}

aDepartment of Chemical Engineering, Institute of Chemical \& Environmental Technologies, University of Castilla-La Mancha, Campus Universitario s/n, 13071 Ciudad Real, Spain

${ }^{\mathrm{b}}$ Department of Chemical Engineering, Faculty of Chemical Sciences \& Technologies, University of Castilla-La Mancha, Campus Universitario s/n, 13071 Ciudad Real, Spain ${ }^{c}$ Geo-environmental Group, Civil Engineering School, University of Castilla-La Mancha, Avda. Camilo José Cela s/n, 13071 Ciudad Real, Spain

\begin{abstract}
In this work, a three-month test is used to evaluate the role of electrokinetic fences in the prevention of the diffusion of herbicide in case of accidental spills of large amounts of highly concentrated products in clay soil. To do this, a mock-up $\left(0.95 \times 2.00 \times 0.50 \mathrm{~m}^{3}\right)$ is used and an electrokinetic fence is placed far away from the hydraulic plume in order to mitigate the effect of the diffuse pollution caused by the spill of an important amount of 2,4-dichlorofenoxiacetic acid (2,4-D) and oxyfluorfen. The results confirm that diffusion of pollutants is important and that the presence of an electrokinetic fence can contain micellar pollutants and help to minimize the trespassing of soluble pollutants, although they cannot fully prevent this trespass. The results obtained in this work are compared to those obtained in previous works, in which fence technology with surrounding electrode placement was evaluated and important differences were pointed out; this has generated valuable data for the design of this technology.
\end{abstract}




\section{Keywords}

electrokinetic, fence, soil, herbicide, oxyfluorfen, 2-4-D

\section{Highlights}

- Electrokinetic fences help to prevent diffuse pollution of herbicides

- Results obtained by electrokinetic fences depend on the strategy used

- Electrokinetic fences are more effective with non-soluble herbicides

- Linear alternating placement of electrodes minimizes the negative effects of electrolysis on $\mathrm{pH}$

- Drying effect of the linear electrokinetic fence in the nearness of the electrodes row

\footnotetext{
*Author to whom all correspondence should be addressed: manuel.rodrigo@uclm.es
} 


\section{Introduction}

Despite being a reference technology for the remediation of soil polluted with metal ions, the application of electrokinetic processes for the remediation of soil polluted with organics can be considered as a relatively recent topic, which has attracted more and more attention in recent years because of the interesting results obtained by different research groups all around the world [1-3]. Electrode arrangement is one of the key factors in electrokinetic technology, because it fixes the fluxes of the different species (water, pollutants) in the electro-remediated zone $[4,5]$. According to the literature, there are other arrangements that can be used to flush the pollutants from soil, replacing the wellknown pump and treat processes in soils with low permeability by others that prevent dispersion by fencing the pollution in a restricted narrow zone.

Regardless of the type of treatment, two parameters seem to have a great influence on the application of electrokinetic soil remediation processes. One is the solubility of the pollutant in water, related to the necessity of adding surfactants in the flushing fluid formulation, in order to mobilize the pollutant. The other is the vapor pressure, which is related to the relevance of the volatilization during the treatment that, in turn, is known to be promoted in electrokinetic processes because of the rise in the temperature caused by the ohmic heating [6-19]. Two good models of pollutants for testing are oxyfluorfen and 2,4-dichlorofenoxiacetic acid (2,4-D), because they have a very different solubility but a similar vapor pressure. Thus, oxyfluorfen has low water solubility $\left(0.1 \mathrm{mg} \mathrm{dm}^{-3}\right.$ at $22^{\circ} \mathrm{C}$ ) and a vapor pressure of $0.026 \mathrm{mPa}$ at $25^{\circ} \mathrm{C}$, while $2,4-\mathrm{D}$ has a great solubility in water $\left(900 \mathrm{mg} \mathrm{dm}^{-3}\right)$ and a very similar vapor pressure of $0.020 \mathrm{mPa}$ at $25^{\circ} \mathrm{C} \mathrm{[20].}$

In previous works, we have evaluated in 180 L-mock-ups the remediation of soils polluted with oxyfluorfen and 2,4-D with different EK based technologies, including EKSF 
(electrokinetic soil flushing) with linear rows of faced electrodes [21, 22], EKSF with surrounding electrodes configurations 1C6A (one cathode surrounded by six anodes) and 1A6C (one anode surrounded by six cathodes) [23, 24], and electrokinetic fence (EKF) technologies with surrounding configurations of alternating electrodes [25]. From these works, it was concluded that:

- dispersion of the pollutant was very rapid once an accidental spill was simulated and

- the technology applied (in particular the electrodes distribution) was very relevant to the results attained, because it determined the total efficiency of the removal of pollutants from soil.

For the removal of oxyfluorfen, the EKF - the process in which the pollution point is surrounded by a circular configuration of alternating electrodes - was found to be the most efficient technology, being the dragging of micelles to the cathode, the primary electrokinetic mechanism, although the electrophoresis of micelles towards the anode was also important in order to explain the experimental observations. This was not an expected outcome, because this configuration was proposed as an electrokinetic fence to prevent pollution dispersion and not as a remediation technology. However, it was found inefficient in the prevention target but very efficient in the removal of the micellar herbicide $[25,26]$.

On the other hand, for the removal of 2,4-D, which is known to be a herbicide with high solubility in water, the application of EKSF with a 1C6A configuration allowed us to reach the best removals. In this case, the primary mechanism was the efficient transport of the 2,4-D to the anodes by electromigration, which is promoted in this specific technology by the high number of anodes used. 
In addition to the electrokinetic transport mechanisms, another key outcome made in our previous studies at bench-scale was the relevance of the volatilization mechanisms, which explain the very high transport of pollutants to the atmosphere, and that obliges in a real treatment to include polluted gas treatment technologies in the complete remediation scheme. This volatilization also develops in non-remediated soils, although the increase in the temperature associated with the ohmic heating caused by the application of an electric field during electrokinetic remediation technologies strongly promotes it.

Notwithstanding this, all these technologies were not found to be efficient in retaining the pollution in the soil, which means that it is still important to study this issue further. Thus, despite the large size of the bench-scale plants used (especially if compared to most studies found in the literature), the rapid transport of the pollutant through all the set-up after the simulated accidental spill does not allow us to reach conclusions about the possibility of containing the pollution in real cases. For this reason, in this work we are simulating an accidental spill of a mixture of 2,4-D and oxyfluorfen, in a mock-up with a dedicated hydraulic flow pattern. In this case study, we have placed the EK fence at a relatively large distance, in order to confirm if there is a way to avoid pollution dispersion in places far away from hydraulic plumes with EK processes. It is important to take into account that in real situations the hydraulic plume can flush pollution (by combination with a water treatment technology) and that a key problem can be the dispersion, by diffusion, of the pollution to places far away from this plume.

\section{Materials and Methods}

Experimental set-up. A scheme of the process aimed to be studied is displayed in Figure 1A. The clay soil used in this study was from a quarry located in Toledo (Spain), and its characterization and preparation for the experiments is described elsewhere [27]. The 
bench scale plant was a methacrylate prism with a soil capacity of $950 \mathrm{dm}^{3}$ (LWH: $200 \times 95 \times 50 \mathrm{~cm}^{3}$ ), in which $1 \times 1 \times 10 \mathrm{~cm}^{3}$ graphite rods were connected to a power supply (400 SM-8-AR ELEKTRONIKA DELTA BV) and were used as positive and negative electrodes, being positioned in semi-permeable electrolyte wells. Figure 1B presents the instrumentation of the plant including feed-wells and electrode-wells (anodic and cathodic wells), tensiometers and thermocouples. A constant voltage gradient of 1.0 VDC $\mathrm{cm}^{-1}$ was applied between each consecutive pair of electrodes. The reactor was designed to separate and collect the fluids through an outlet situated on one of the sidewalls of the reactor, which was used to simulate the hydraulic plume. To monitor the flux of water and the temperature evolution during the experiment, tensiometers and thermocouples were inserted into the soil.

A)

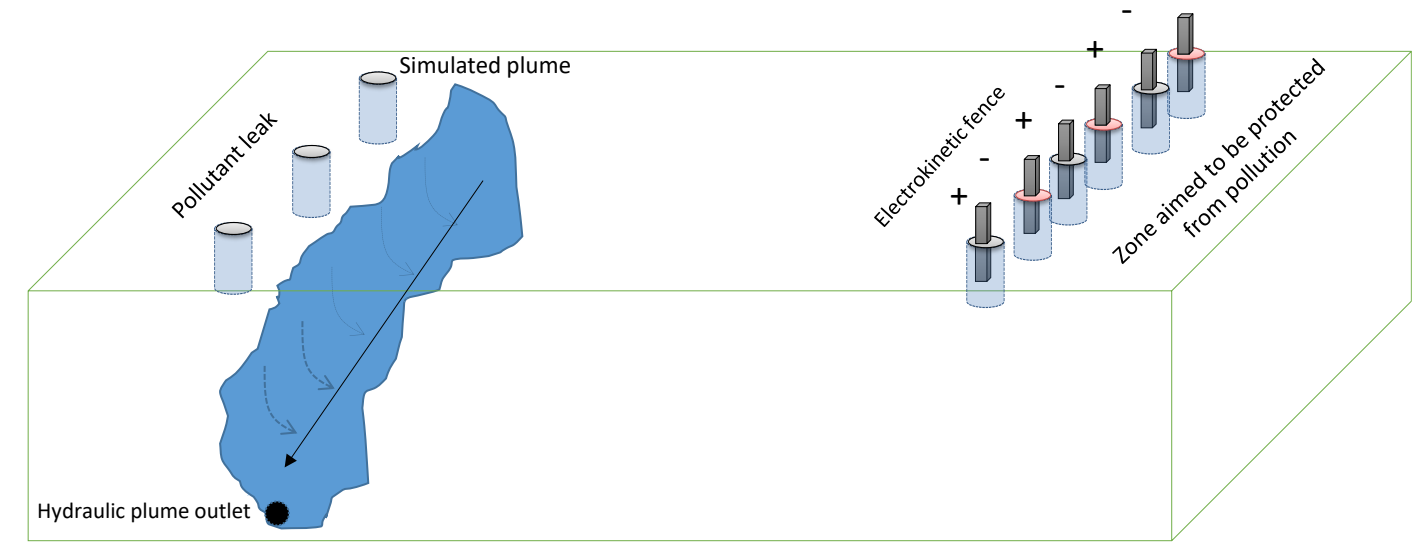

B)

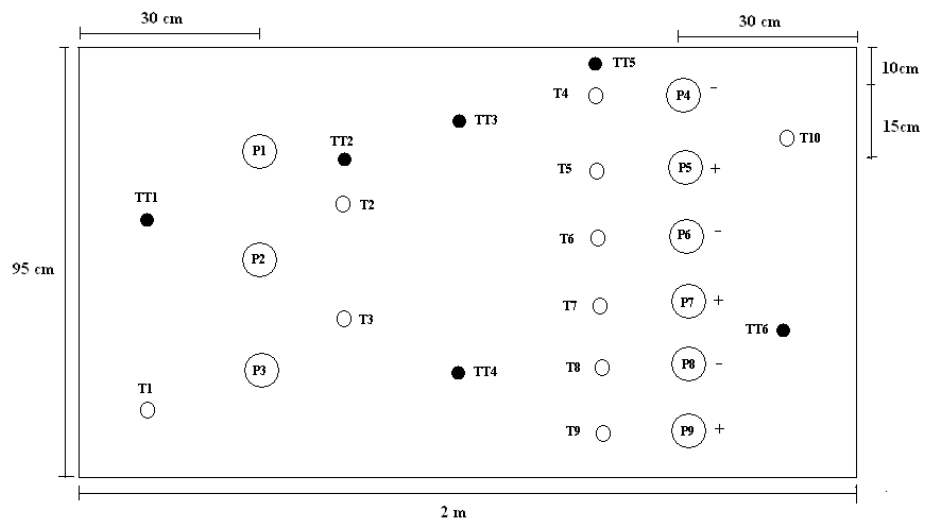


Figure 1. A) Layout of the process studied; B) Arrangements of the wells and sampling points: $\mathrm{P}_{1}-\mathrm{P}_{3}$ : feed wells; $\mathrm{P}_{4}-\mathrm{P}_{9}$ : electrode-wells; $\mathrm{T}_{1}-\mathrm{T}_{10}$ : tensiometers; $\mathrm{TT}_{1}-\mathrm{TT}_{6}$ : thermocouples.

Experimental procedure. Once the plant was fully instrumented, the experimental procedure began with the pollution of the soil (simulating an accidental spill over 71 days). Thus, in one side of the mock-up, where the feed wells were, an accidental leak of $11.6 \mathrm{~g}$ of 2,4-D and $11.6 \mathrm{~g}$ of Fluoxil 24 EC (oxyfluorfen 24\%) was simulated over 71 days $\left(0.166 \mathrm{mg}\right.$ of each herbicide $\left.\mathrm{d}^{-1}\right)$. In addition, a hydraulic flux of $0.648 \mathrm{dm}^{3} \mathrm{~d}^{-1}$ was also induced (water, $\mathrm{pH} 7.64$ and $0.391 \mathrm{mS} \mathrm{cm}^{-1}$ of conductivity). This hydraulic flux was added in the feed wells and collected in a special outlet made at the bottom part of one of the walls of the mock-up.

The test started when the power source, a 400 SM-8-AR ELEKTRONIKA DELTA BV, was turned on and applied a constant voltage gradient of $1.0 \mathrm{~V} \mathrm{~cm}$. During the experiment, the electrical current, temperature, $\mathrm{pH}$, conductivity, 2,4-D concentration and oxyfluorfen concentration of the hydraulic fluid were monitored. The hydraulic plume outlet was sampled daily. The anodic and cathodic wells could not be sampled regularly because it was a complicated process to keep the wells filled. At the end of the experiment, an in-depth sectioned analysis of the complete soil section was conducted (post-mortem analysis) by dividing the set-up into 87 pieces in order to obtain 2-D and 3-D maps of different parameters such as $\mathrm{pH}$, conductivity, moisture, 2,4-D concentration and oxyfluorfen concentration.

Analyses. The oxyfluorfen and 2,4-D concentration were determined by high performance liquid chromatography (HPLC), using an Agilent 1100 (Agilent 
Technologies, Palo Alto, California, EEUU) with a UV detector (220 nm) and a $150 \mathrm{x}$ $3.0 \mathrm{~mm}$ Phenomenex Gemini $5 \mu \mathrm{m} \mathrm{C} 18$ column. The flow rates used were $0.6 \mathrm{~cm}^{3} \mathrm{~min}^{-}$ ${ }^{1}$ of acetonitrile $(70 \%) /$ water $(30 \%)$ for oxyfluorfen and $0.6 \mathrm{~cm}^{3} \mathrm{~min}^{-1}$ of acetonitrile (40\%) / water, with $0.1 \%$ phosphoric acid (60\%) for 2,4-D. To quantify the amount of oxyfluorfen in the liquid samples, an L-L extraction process was carried out in Eppendorf tubes $\left(15 \mathrm{~cm}^{3}\right)$, using acetonitrile as the solvent (ratio $\left.=1 \mathrm{w} / \mathrm{w}\right)$. Both phases were vigorously stirred in a vortex mixer (VV3 VWR multi-tube) for five min. before injection into the HPLC. To quantify the amount of oxyfluorfen in the soil, an L-S extraction process was performed in Eppendorf tubes $\left(15 \mathrm{~cm}^{3}\right)$, using acetonitrile as the solvent (ratio of polluted soil/solvent $=0.4 \mathrm{w} / \mathrm{w}$ ). Both phases were vigorously stirred in a vortex mixer (VV3 VWR multi-tube) for five min., and subsequent phase separation was accelerated using a centrifuge rotor angular (CENCOM II P-elite) for $20 \mathrm{~min}$. at 4000 rpm, before injection into the HPLC. To quantify the amount of 2,4-D in the soil, the same L-S extraction process was used but using water as solvent. Measurements of $\mathrm{pH}$ and electric conductivity were completed using an InoLab WTW pH-meter and a GLP 31 Crison conductivity meter respectively. The electric current was measured with a KEITHLEY 2000 Digital Multimeter. The temperature measurements were performed with PT-100 thermocouples. 


\section{Results and Discussion}

Figure 2 shows the current intensity produced by the electric field of $1.0 \mathrm{~V} \mathrm{~cm}^{-1}$ between each consecutive anode and cathode. As can be seen, for every day there is an abrupt decrease from an initial value, which shows an increasing trend with time, down to zero; this corresponds to the depletion of water from soil in the electrolyte wells. Water was added once a day, and after this addition, the intensity increased quickly, up to the maximum daily value. This means that this configuration of electrodes dries the soil in the immediacy of the electrode zone and requires the permanent addition of water into the wells in order to get a suitable performance. This is an important difference with respect to what was observed in the case of EKF with a circular configuration of electrodes, for which the water content of the soil did not generate any operational problem during the tests $[28,29]$. In fact, with that surrounding electrode configuration, the water content of the soil increased importantly, especially when results were compared to those obtained in a reference test without application of an electric field. The amounts of water added during the operation tests are shown in Part b of Figure 2. Most of the water was added in the anode, but it was not collected in the cathode (as expected, according to electro-osmotic flux direction), because the volumes of the liquid contained in both types of wells (anodic and cathode) decreased. 

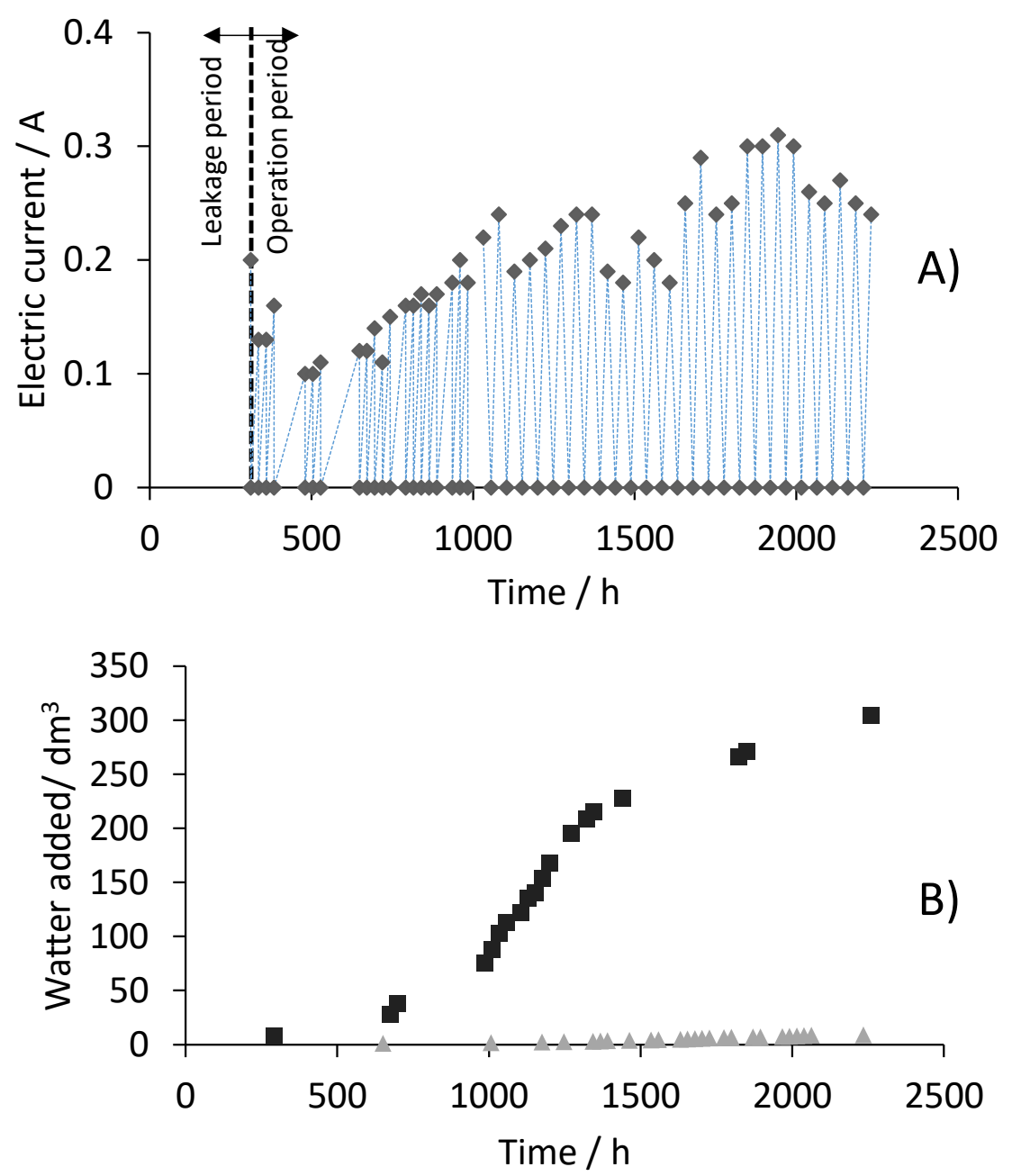

Figure 2. A) Current intensity ( $\bullet$ ); B) Total volume of water added in the anolyte ( $\square$ ) and catholyte $(\triangle)$ wells in order to keep the operational levels. Leakage period: time elapsed from the start of the spill until power source was switched on.

Another important observation related to water comes from hydraulic fluxes. Because of the configuration tested, most of the polluted water added to the soil in the simulated spill was expected to be collected in the plume outlet, from which, in a real situation, a pump and treat process might be applied in order to remove pollution. Figure 3 gives information about the $\mathrm{pH}$, conductivity and herbicides dragged with this flux. In addition, information about the volumes of water that were added to simulate the hydraulic flux, 
and that were collected in the outlet made to collect this flux, are also shown. Differences correspond to the evaporation flux.
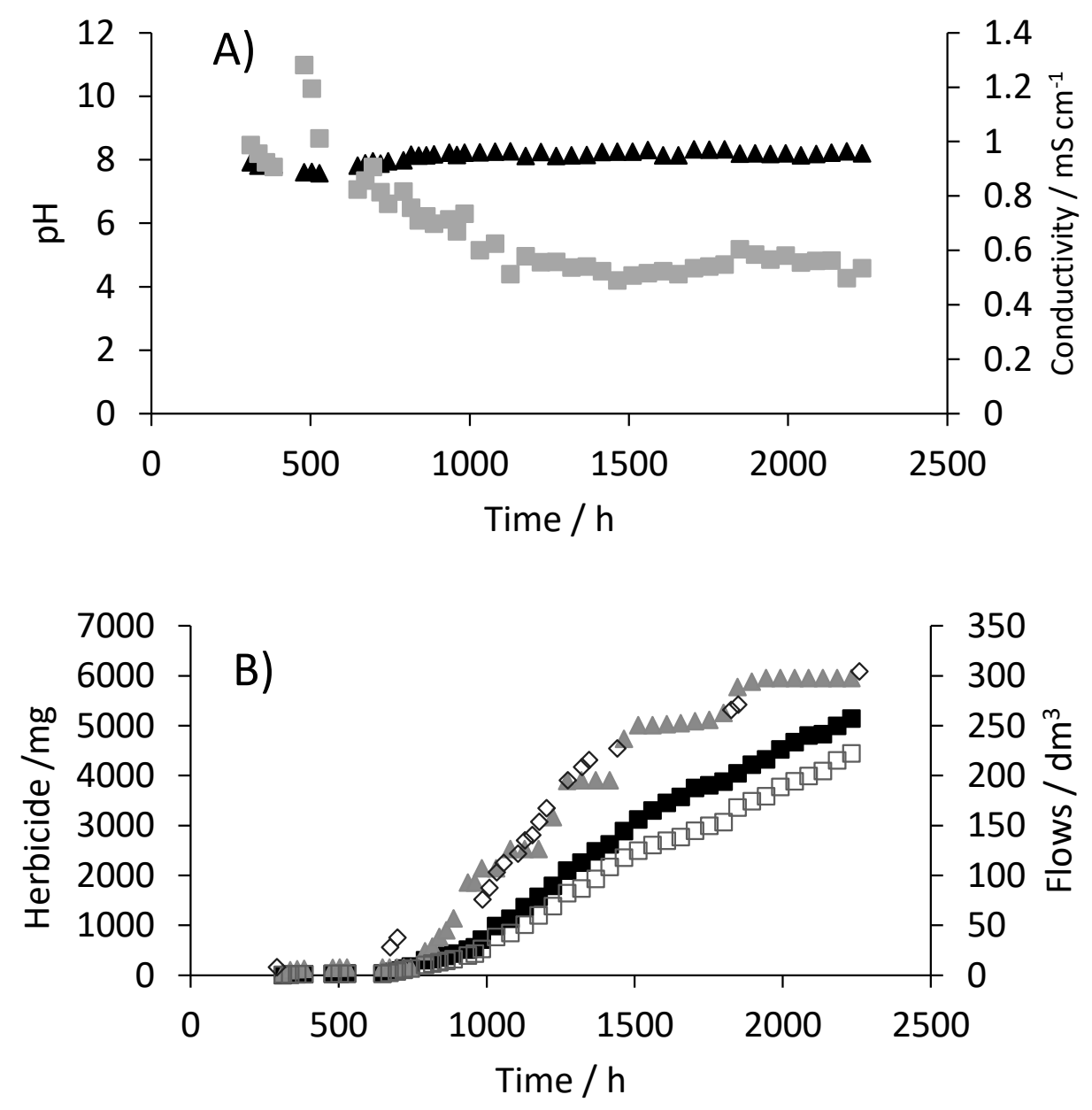

Figure 3. A) Changes during the test in the concentrations of $\mathrm{pH}(\boldsymbol{\Delta})$ and conductivity ( $\square)$; and B) Changes during the test in the amount of oxyfluorfen ( $\square)$, amount of 2,4-D $(\Delta)$, total volume of water collected in the hydraulic flux collector $(\square)$ and total volume of water added to the mockup $(\diamond)$

As can be observed, there is not an important change in the $\mathrm{pH}$ but just a small increase in its value during the three-month operation test. Regarding conductivity, it decreases down to a constant value, reflecting the transient interaction of the water flow with the soil, which partially drags the salts contained in it. In comparing the volume and amount of herbicide, it can be confirmed that the plume outlet is the point in which more than 
$40 \%$ of the spilled pollution $(51.32 \%$ in the case of the $2,4-\mathrm{D}$ and $44.30 \%$ in the case of oxyfluorfen) is transported. This means that there is still an important part of this pollution that is transported to other different parts of the mock-up (or it is transported to the atmosphere, as has been pointed out in previous works of our group)[30, 31]. Hence, there is a real necessity for a fence in order to prevent pollution diffusion.

After approximately three months of operating the test, a post-mortem analysis was carried out on the soil in order to obtain 2-D maps of the most important parameters, trying to learn how pollution has been transported in this particular case.

Figure 4 shows the water distribution 2-D map after the 3-month test. The drying effect of the linear electrokinetic fence in the immediacy of the electrodes line can be seen. This dry zone is not placed exactly over the line that links the wells, but close to it. This shift can be explained in terms of the daily addition of water in the electrode wells, which contributes to increase the water content in just the zone where the electrodes wells are placed. The effect of the boundaries electrodes and how the water content is higher in the first anode of the row and lower in the last cathode of the row is also remarkable. Likewise, the higher water content of the zone in which the plume is simulated is also observed in this figure. This higher water content was expected, as was its effect on other parameters, such as the $\mathrm{pH}$ and conductivity.

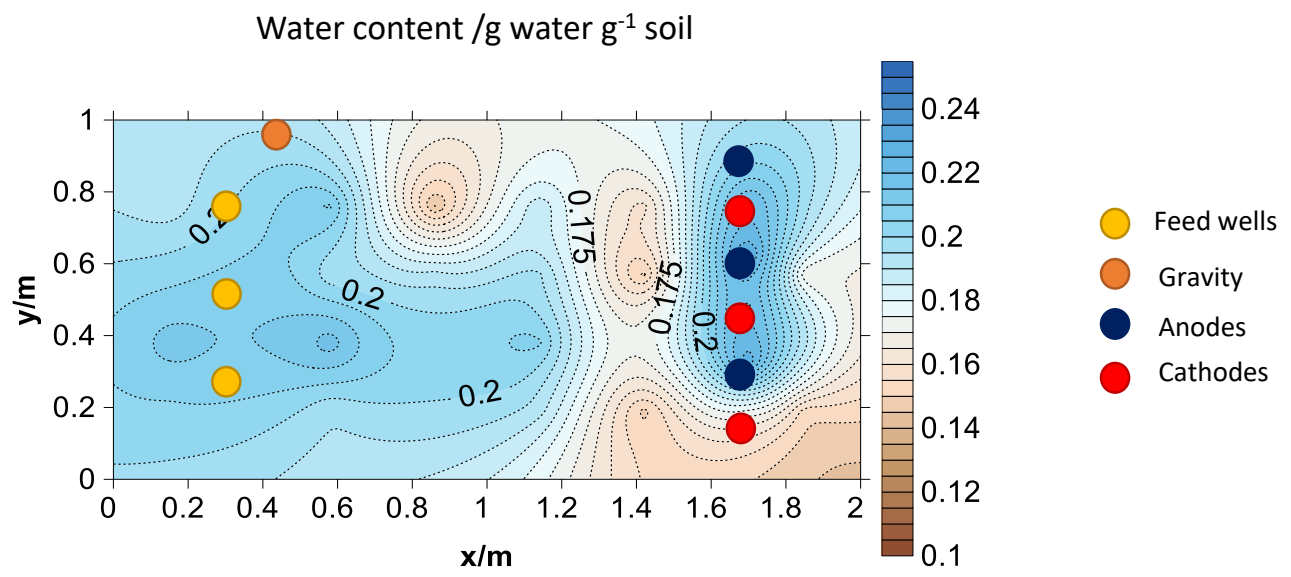


Figure 4. 2-D map of the distribution of water content in soil after the three-month test

Thus, it is also interesting to study the maps of $\mathrm{pH}$ and conductivity shown in Figure 5, which, together with the information given in Figure 3, allow us to confirm the dragging of salts from soil and the low effect of the electrokinetic fence on the $\mathrm{pH}$ in regions far away from the nearness of the electrodes. This is clearly reflected in the narrow zone around the electrodes, in which the $\mathrm{pH}$ undergoes modifications, which becomes a clear difference with respect to our previous study in which we evaluated the EKF in smaller scale and with a circular electrode configuration.

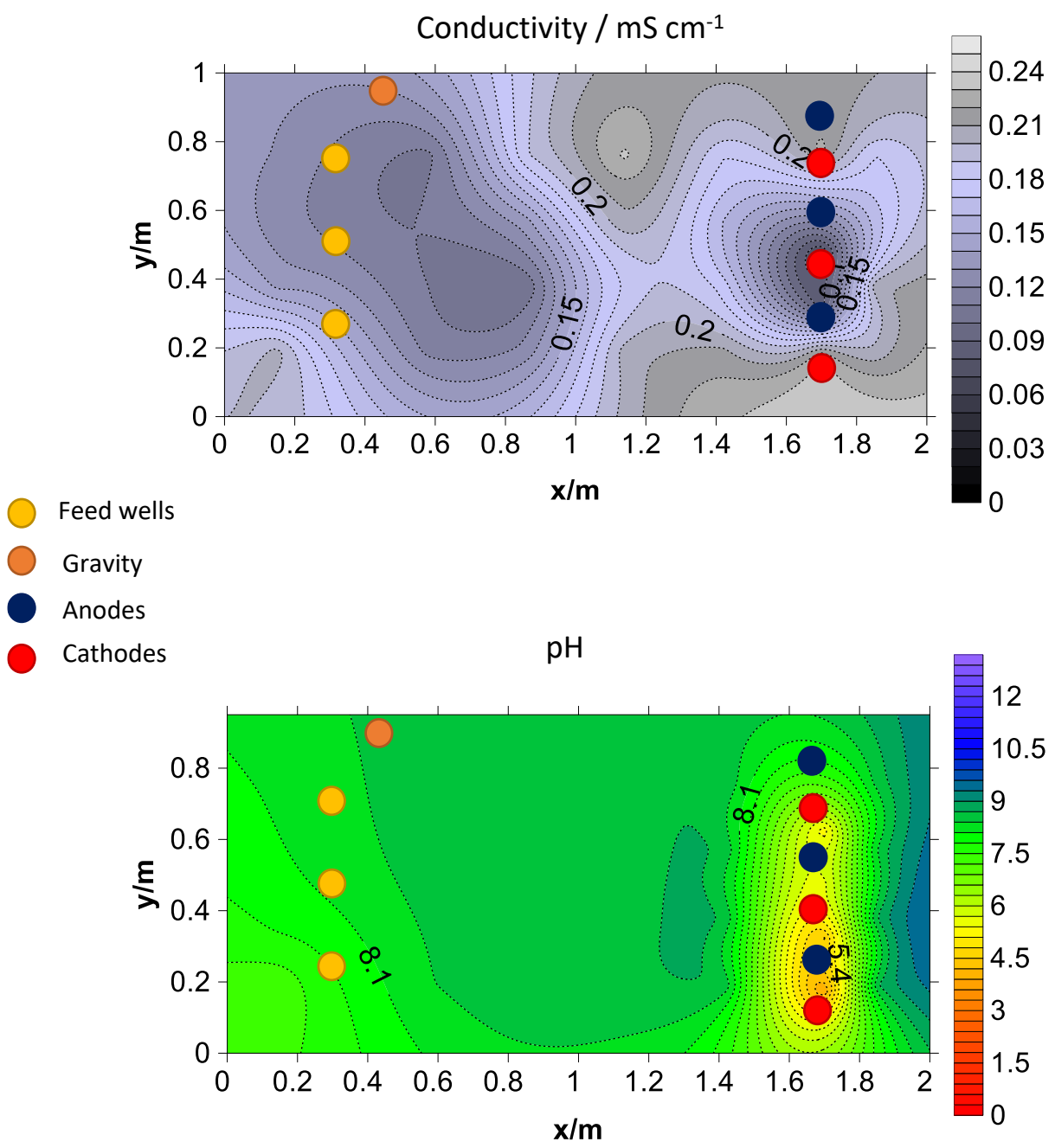

Figure 5. 2-D map of $\mathrm{pH}$ and conductivity after the test 
Thus, in this study, regarding $\mathrm{pH}$, there are only significant variations in the proximities of the electrodes, and these changes are much lower than others reported in previous studies, clearly indicating the neutralization of the acidic and basic fronts produced between each part of the electrodes. It is also important to remark on the unevenness of the distribution of conductivity, which supports the dragging of salts in the zone of the hydraulic plume and the small changes in the nearness of the wells caused by the acidic and basic fronts.

However, the most interesting point of this work is the distribution of the herbicides after more than three months of operation. The 2,4-D and oxyfluorfen distributions are shown in Figure 6.

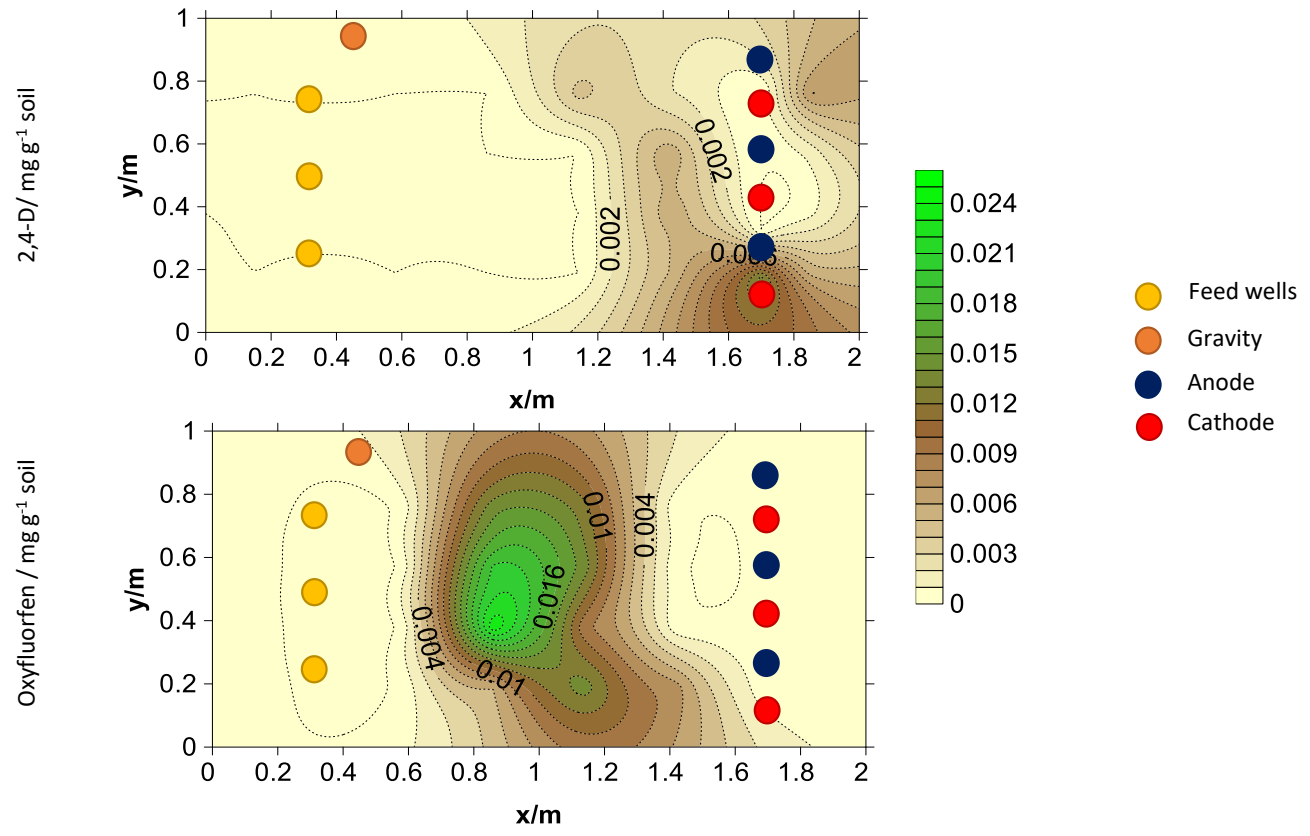

Figure 6. 2-D map of 2,4-D and oxyfluorfen distribution after the test

As is evident, a completely different behavior can be observed for both species. While the effectiveness of the EK fence is complete with oxyfluorfen and, up to the detection limits of the HPLC, no oxyfluorfen was detected after the fence, this is not the case for 
the $2,4-\mathrm{D}$, for which $2.3 \%$ of the $2,4-\mathrm{D}$ spilled was able to cross the fence and hence leak from the remediation site. This is in agreement with previous results in which it was observed that this technology is more effective for the retention of non-soluble species. On the contrary, the amount of herbicide retained before the fence in the narrow zone where the water content was lower must be pointed out, and this higher drought can act as a capillary barrier to prevent volatilization of the pollutants. Thus, the percentage of oxyfluorfen retained in this zone is $16.03 \%$, while the percentage of $2,4-\mathrm{D}$ is $4.66 \%$. This means that this dryness can be responsible for the contention of the pollution, even more than the desired effect of entrapping pollution inside the electro-osmotic fluxes generated between electrodes. Regarding the amount of 2,4-D and oxyfluorfen volatilized, they can be estimated by mass balance and results of $41.72 \%$ and $39.67 \%$, respectively. These results are in agreement with previous tests carried out, in which the significance of the volatilization was pointed out, and also with the vapor pressure of both species, which is known to be $0.02 \mathrm{mPa}$ for $2,4-\mathrm{D}$ and $0.026 \mathrm{mPa}$ for oxyfluorfen at $25^{\circ} \mathrm{C}$.

In previous studies, we have evaluated fence technology in surrounding electrode placement configurations at two different scales, pilot and prototype, for remediation tests that lasted for approximately one month of operation [25, 26, 32, 33]. We did this work at two different scales, one slightly smaller $(175 \mathrm{~L})$ than the use in this work and the other much higher $(32.000 \mathrm{~L})$, and the main results obtained in that work and in the present study are summarized in Table 1 . It is important to remark that data obtained in those pieces of work are not completely comparable, as the experimental boundary constraints were not only different between them but were also different with respect to those of the test shown in this work. However, the large size of these tests and the difficulty in making replications (not only because of size and the time spent in the preparation of the mockups or prototypes, but also, most importantly, because of the very high costs associated with this research) advise us to try to do a qualitative comparison with these results. 
Table 1. Mass balances of oxyfluorfen and 2,4-D after the remediation of soil in tests

\begin{tabular}{|l|c|c|c|c|c|c|}
\hline \multirow{2}{*}{ Percentage of herbicide... } & \multicolumn{2}{|c|}{ Pilot plant } & \multicolumn{2}{c|}{ prototype } & \multicolumn{2}{c|}{ Bench-scale plant } \\
\cline { 2 - 7 } & oxy (\%) & 2,4-D (\%) & oxy (\%) & 2,4-D (\%) & oxy (\%) & 2,4-D (\%) \\
\hline ...extracted in anode wells & 3.03 & 6.69 & 0.01 & 0.00 & 0.0 & 0.0 \\
\hline $\begin{array}{l}\text {..extracted in cathode } \\
\text { wells }\end{array}$ & 23.77 & 8.33 & 0.26 & 0.32 & 0.0 & 0.0 \\
\hline $\begin{array}{l}\text {...extracted during } \\
\text { sampling }\end{array}$ & 8.33 & 0.11 & 0.00 & 0.00 & 0.0 & 0.0 \\
\hline $\begin{array}{l}\text {...collected in hydraulic } \\
\text { fluxes }\end{array}$ & 5.40 & 6.74 & 0.00 & 0.00 & 44.30 & 51.32 \\
\hline ...volatilized & 35.27 & 26.85 & 85.20 & 87.16 & 39.67 & 41.72 \\
\hline $\begin{array}{l}\text {...contained in the } \\
\text { soil after } \\
\text { treatment... }\end{array}$ & 24.20 & 51.28 & 14.53 & 12.52 & 16.03 & 6.96 \\
$\begin{array}{c}\text {... and it has } \\
\text { crossed the } \\
\text { fence } \\
\text {...and it is } \\
\text { entrapped } \\
\text { within the } \\
\text { fence } \\
\text { delimited area }\end{array}$ & 12.89 & 41.54 & 2.81 & 1.60 & 0.0 & 2.30 \\
\cline { 2 - 7 } & 11.31 & 9.74 & 11.72 & 10.92 & 16.03 & 4.66 \\
\hline
\end{tabular}

In comparing these data (using circular placements of electrodes at two different scales) with those obtained in this work in which the same technology was used to try to contain pollution, important differences arise:

- In the systems at low scale (a mock-up of 175 L) (and within a one-month test), the amount of herbicides that have crossed the fence after the treatment is much higher, and reached $41.54 \%$ in the case of the soluble $2,4-\mathrm{D}$ and $12.89 \%$ in the case of the micellar oxyfluorfen. This important trespassing was considered as a failure from the viewpoint of retention, although not from the perspective of treatment. However, despite the fact that in this case the fence was not efficient for the purpose for it was planned, these results point out that this technology is more effective for the retention of non-soluble species, because the diffusion and the electromigration of the soluble herbicides lead to important leaks.

- The larger the set-up, the higher are the percentages of herbicides volatilized. This has been explained in terms of the much higher ohmic drops associated with the 
distance between electrodes (for the same electric field), which lead to higher operational temperatures. Results obtained in this work allow us to confirm this tendency.

- Differences in the percentages of herbicides dragged by the hydraulic fluxes can be explained by the boundary constraints of the system more than by the scale of the plant. Nonetheless, the larger the scale of the study, the lower is the impact of the electrokinetic processes and the higher the influence on results of the electric heating.

- Despite the fact that the main removal mechanism in the prototype is the volatilization, and that electrokinetic processes are not favored at this scale, there is a non-negligible fraction of the two herbicides that cross the fence (especially in comparison with those transported by EK). Nevertheless, at this scale the fence can be considered as efficient, in particular if percentages of the herbicides inside and outside the fence are compared. This results in advice against conclusions obtained from a very small scale, because the rapid transport of pollutants in comparison with the dimensions of the mock-ups reduces the utility of the fence.

- Opposite to the configuration tested in this work, in the prototype there was also some leak of oxyfluorfen, which indicates that the surrounding configuration of the fence technology is not adequate to contain the pollution contained in a soil if the hydraulic fluxes go through it, because these fluxes may drag the pollution outside the fence. On the contrary, the strategy evaluated in this work is more effective, which helps to prevent the diffused polluting in places far away from the spill.

This comparison is of great importance, because it gives valuable information about the future use of fence technology for the retention of the pollution contained in soils.

\section{Conclusions}


Electrokinetic fences may help to contain pollution associated with herbicides in places far away from the spills and not included in the same direction of the hydraulic fluxes. It is more efficient with micellar pollutants than with soluble pollutants and in this latter case, the fence is not completely efficient and a small amount of the herbicides are able to cross it. Using a row of electrodes leads to the drying of the soil in the nearness of the electrode line, and this reduction in the water content is related to the entrapping action of the fence. Changes of the $\mathrm{pH}$ with this row configuration of electrodes in the fence have nothing to do with those obtained in surrounding electrodes configurations. With rows of electrodes, the effects of the acidic and basic fronts are almost negligible. The size of the mock-ups used to study this technology is important because of the rapid diffusion of the herbicides.

\section{Acknowledgements}

Financial support from the Spanish Ministry of Economy, Industry and Competitiveness and the European Union, through project CTM2016-76197-R (AEI/FEDER, UE), is gratefully acknowledged.

\section{References}

[1] M.A. Rodrigo, N. Oturan, M.A. Oturan, Electrochemically Assisted Remediation of Pesticides in Soils and Water: A Review, Chemical Reviews, 114 (2014) 8720-8745.

[2] J. Virkutyte, M. Sillanpaa, P. Latostenmaa, Electrokinetic soil remediation - critical overview, Science of the Total Environment, 289 (2002) 97-121.

[3] A.N. Alshawabkeh, A.T. Yeung, M.R. Bricka, Practical aspects of in-situ electrokinetic extraction, Journal of Environmental Engineering-Asce, 125 (1999) 27-35.

[4] M.T. Alcantara, J. Gomez, M. Pazos, M.A. Sanroman, Electrokinetic remediation of PAH mixtures from kaolin, Journal of Hazardous Materials, 179 (2010) 1156-1160.

[5] M.T. Alcantara, J. Gomez, M. Pazos, M.A. Sanroman, Electrokinetic remediation of lead and phenanthrene polluted soils, Geoderma, 173 (2012) 128-133.

[6] H.I. Gomes, C. Dias-Ferreira, A.B. Ribeiro, Electrokinetic remediation of organochlorines in soil: Enhancement techniques and integration with other remediation technologies,

Chemosphere, 87 (2012) 1077-1090. 
[7] S.A. Jackman, G. Maini, A.K. Sharman, G. Sunderland, C.J. Knowles, Electrokinetic movement and biodegradation of 2,4-dichlorephenoxyacetic acid in silt soil, Biotechnology and Bioengineering, 74 (2001) 40-48.

[8] A. Karagunduz, A. Gezer, G. Karasuloglu, Surfactant enhanced electrokinetic remediation of DDT from soils, Science of the Total Environment, 385 (2007) 1-11.

[9] A.Y. Kolosov, K.I. Popov, N.A. Shabanova, A.A. Artem'eva, B.M. Kogut, A.S. Frid, V.Y. Zel'venskii, E.M. Urinovich, Electrokinetic removal of hydrophobic organic compounds from soil, Russian Journal of Applied Chemistry, 74 (2001) 631-635.

[10] X. Lu, S. Yuang, Electrokinetic removal of chlorinated organic compounds, in: K.R. Reddy, C. Cameselle (Eds.) Electrochemical Remediation Technologies for Polluted Soils, Sediments and Groundwater, C. John Wiley \& Sons Inc., Hoboken, 2009, pp. 223-227.

[11] J.W. Ma, F.Y. Wang, Z.H. Huang, H. Wang, Simultaneous removal of 2,4-dichlorophenol and $\mathrm{Cd}$ from soils by electrokinetic remediation combined with activated bamboo charcoal, Journal of Hazardous Materials, 176 (2010) 715-720.

[12] A.M. Polcaro, A. Vacca, M. Mascia, S. Palmas, Electrokinetic removal of 2,6-dichlorophenol and diuron from kaolinite and humic acid-clay system, Journal of Hazardous Materials, 148 (2007) 505-512.

[13] K.R. Reddy, K. Maturi, C. Cameselle, Sequential Electrokinetic Remediation of Mixed Contaminants in Low Permeability Soils, Journal of Environmental Engineering-Asce, 135 (2009) 989-998.

[14] K.R. Reddy, K. Darko-Kagya, A.Z. Al-Hamdan, Electrokinetic Remediation of Pentachlorophenol Contaminated Clay Soil, Water Air and Soil Pollution, 221 (2011) 35-44.

[15] A.B. Ribeiro, J.M. Rodriguez-Maroto, E.P. Mateus, H. Gomes, Removal of organic contaminants from soils by an electrokinetic process: the case of atrazine. Experimental and modeling, Chemosphere, 59 (2005) 1229-1239.

[16] A.B. Ribeiro, E.P. Mateus, J.-M. Rodriguez-Maroto, Removal of organic contaminants from soils by an electrokinetic process: The case of molinate and bentazone. Experimental and modeling, Separation and Purification Technology, 79 (2011) 193-203.

[17] C.-H. Weng, Y.-T. Lin, T.Y. Lin, C.M. Kao, Enhancement of electrokinetic remediation of hyper- $\mathrm{Cr}(\mathrm{VI})$ contaminated clay by zero-valent iron, Journal of Hazardous Materials, 149 (2007) 292-302.

[18] S. Yuan, M. Tian, X. Lu, Electrokinetic movement of hexachlorobenzene in clayed soils enhanced by Tween 80 and beta-cyclodextrin, Journal of Hazardous Materials, 137 (2006) 1218-1225.

[19] S.-h. Yuan, J.-z. Wan, X.-h. Lu, Electrokinetic movement of multiple chlorobenzenes in contaminated soils in the presence of beta-cyclodextrin, Journal of Environmental SciencesChina, 19 (2007) 968-976.

[20] E. Vieira dos Santos, F. Souza, C. Saez, P. Cañizares, M.R.V. Lanza, C.A. Martinez-Huitle, M.A. Rodrigo, Application of electrokinetic soil flushing to four herbicides: A comparison, Chemosphere, 153 (2016) 205-211.

[21] C. Risco, R. Lopez-Vizcaino, C. Saez, A. Yustres, P. Canizares, V. Navarro, M.A. Rodrigo, Remediation of soils polluted with 2,4-D by electrokinetic soil flushing with facing rows of electrodes: A case study in a pilot plant, Chemical Engineering Journal, 285 (2016) 128-136. [22] C. Risco, S. Rodrigo, R. Lopez Vizcaino, A. Yustres, C. Saez, P. Canizares, V. Navarro, M.A. Rodrigo, Removal of oxyfluorfen from spiked soils using electrokinetic soil flushing with linear rows of electrodes, Chemical Engineering Journal, 294 (2016) 65-72.

[23] C. Risco, S. Rodrigo, R. Lopez-Vizcaino, C. Saez, P. Canizares, V. Navarro, M.A. Rodrigo, Electrokinetic flushing with surrounding electrode arrangements for the remediation of soils that are polluted with 2,4-D: A case study in a pilot plant, Science of the Total Environment, 545 (2016) 256-265.

[24] C. Risco, H. Rubi-Juarez, S. Rodrigo, R. Lopez-Vizcaino, C. Saez, P. Canizares, C. BarreraDiaz, V. Navarro, M.A. Rodrigo, Removal of oxyfluorfen from spiked soils using electrokinetic 
soil flushing with the surrounding arrangements of electrodes, Science of the Total Environment, 559 (2016) 94-102.

[25] C. Risco, S. Rodrigo, R. Lopez-Vizcaino, C. Saez, J. Villasenor, V. Navarro, P. Canizares, M.A. Rodrigo, Electrokinetic Remediation of Soils Polluted With Pesticides: Flushing and Fence Technologies, in: N. Yesiller, D. Zekkos, A. Farid, A. De, K.R. Reddy (Eds.) Geo-Chicago 2016: Sustainable Waste Management and Remediation, 2016, pp. 203-212.

[26] C. Risco, S. Rodrigo, R. López-Vizcaíno, A. Yustres, C. Sáez, P. Cañizares, V. Navarro, M.A. Rodrigo, Electrochemically assisted fences for the electroremediation of soils polluted with 2,4-D: A case study in a pilot plant, Separation and Purification Technology, 156, Part 2 (2015) 234-241.

[27] C. Risco, S. Rodrigo, R. López-Vizcaíno, C. Sáez, P. Cañizares, V. Navarro, M.A. Rodrigo, Electrokinetic flushing with surrounding electrode arrangements for the remediation of soils that are polluted with 2,4-D: A case study in a pilot plant, Science of The Total Environment, 545-546 (2016) 256-265.

[28] C. Risco, S. Rodrigo, R. Lopez-Vizcaino, A. Yustres, C. Saez, P. Canizares, V. Navarro, M.A. Rodrigo, Electrochemically assisted fences for the electroremediation of soils polluted with 2,4-D: A case study in a pilot plant, Separation and Purification Technology, 156 (2015) 234241.

[29] C. Risco, H. Rubi-Juarez, S. Rodrigo, R. Lopez Vizcaino, C. Saez, P. Canizares, C. BarreraDiaz, V. Navarro, M.A. Rodrigo, Removal of oxyfluorfen from spiked soils using electrokinetic fences, Separation and Purification Technology, 167 (2016) 55-62.

[30] E. Vieira dos Santos, C. Saez, P. Canizares, C.A. Martinez-Huitle, M.A. Rodrigo, Reversible electrokinetic adsorption barriers for the removal of atrazine and oxyfluorfen from spiked soils, Journal of Hazardous Materials, 322 (2017) 413-420.

[31] F.L. Souza, C. Saez, M.R.V. Lanza, P. Canizares, M.A. Rodrigo, Removal of chlorsulfuron and 2,4-D from spiked soil using reversible electrokinetic adsorption barriers, Separation and Purification Technology, 178 (2017) 147-153.

[32] R. Lopez-Vizcaino, C. Risco, J. Isidro, S. Rodrigo, C. Saez, P. Canizares, V. Navarro, M.A. Rodrigo, Scale-up of the electrokinetic fence technology for the removal of pesticides. Part I: Some notes about the transport of inorganic species, Chemosphere, 166 (2017) 540-548. [33] R. Lopez-Vizcaino, C. Risco, J. Isidro, S. Rodrigo, C. Saez, P. Canizares, V. Navarro, M.A. Rodrigo, Scale-up of the electrokinetic fence technology for the removal of pesticides. Part II: Does size matter for removal of herbicides?, Chemosphere, 166 (2017) 549-555. 